\title{
Microbiomes in the Context of Refrigerated Raw Meat Spoilage
}

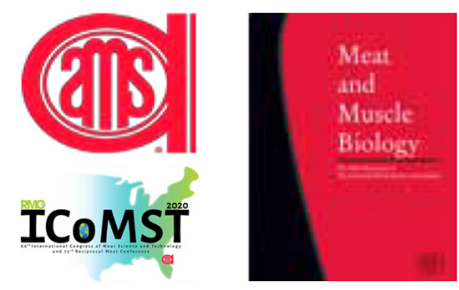

\author{
P. Johansson ${ }^{1}$, E. Jääskeläinen ${ }^{1}$, T. Nieminenn ${ }^{1,+a}$, J. Hultman ${ }^{1,+b}$, P. Auvinen², and K. J. Björkroth ${ }^{1 *}$ \\ ${ }^{1}$ Department of Food Hygiene and Environmental Health, Faculty of Veterinary Medicine, Agnes Sjöbergin katu 2, \\ 00014 Helsinki University, Finland \\ ${ }^{2}$ Institute of Biotechnology, University of Helsinki, Finland, Viikinkaari 5d, 00014 Helsinki University, Finland \\ taPresent Address: Finnish Safety and Chemicals Agency, Opastinsilta 12 B, 00521 Helsinki, Finland \\ tbpresent Address: Department of Microbiology, University of Helsinki, Latokartanonkaari 7, 00014 Helsinki University, \\ Finland*Corresponding author. Email: johanna.bjorkroth@helsinki.fi (P. Johansson)
}

\begin{abstract}
Meat spoilage is a complicated biological phenomenon taking place over the course of time. Several factors influence it, mainly external factors related to packaging and storage temperature but also internal ones related to contamination diversity and product ingredients. We conducted genomic studies of specific spoilage organisms (SSO) and investigated the spoilage microbiomes providing information about the factors that make a specific organism a competitive SSO, as well as the interactions between certain SSO and the most active species and pathways in packaged raw meat. Our studies showed that spoilage microbiomes are diverse, but certain aspects, such as oxygen content or added marinades, shape this diversity strongly. We have also characterized a new spoilage-associated pathway, i.e., heme-dependent respiration capability, in Leuconostoc gelidum subsp. gasicomitatum. The microbiome studies we conducted explain why this species has become a competitive SSO. It is a fast grower and gains advantage for its growth if oxygen is present in the packages. Since the contamination of psychrotrophic lactic acid bacteria is difficult to avoid in meat manufacture, leuconostocs cause spoilage problems from time to time especially in marinated products or those packaged under high-oxygen-containing atmospheres.
\end{abstract}

Key words: meat spoilage, specific spoilage organism, microbiome, modified atmosphere packaging Meat and Muscle Biology 4(2): 12, 1-9 (2020) doi:10.22175/mmb.10369

Submitted 25 February 2020

Accepted 20 May 2020

This paper was accepted as a contribution to the 2020 International Congress of Meat Science and Technology and the AMSA Reciprocal Meat Conference.

\section{Microbial Food Spoilage, Determination and Concept}

Food spoilage and increasing food waste have significant impacts on food security and economics globally. Although it is difficult to evaluate how much of the total food loss is caused by microbes, their role is significant. Due to microbial spoilage, food systems are dependent on refrigeration and packaging to enable provision of perishable foods for consumers. It has been estimated that around $30 \%$ of manufactured food products are spoiled, microbial food spoilage being the major cause (Bourdichon and Rouzeau, 2012).

Microbial food spoilage is a metabolic process that happens over the course of time rendering foods to be undesirable or unacceptable for human consumption due to changes in sensory characteristics. To ensure good food quality throughout the food chain and while consumers handle food items, the industry is demanded to set shelf lives for perishable products, such as meat. When setting shelf life of a food item, the time during which it remains stable and retains its desired qualities should be known. 
Often a manufacturer assigns a shelf life to a product by conducting a shelf life study. A sensory panel of trained individuals is requested to score the characteristics of a food over the course of time, and microbiological analyses (typically the estimation of total concentration of microbes) are done in parallel. The aim is to estimate a time period during which the product is of acceptable quality. The defined time is subsequently applied as shelf life to all production lots. Since microbial contamination and the food spoilage rate vary between different production lots and individual packages, inevitably food acceptable for human consumption ends up rejected, and some food packages reaching consumers are of bad quality or even spoiled before the use-by date.

Even though we know that food waste should be reduced, not much has changed during the last decade in manufacturing practices. Provision of cold and packaging systems with carbon dioxide are the two most important technologies applied to prevent food spoilage. Good manufacturing and hygiene practices are of course elementary in the control of food spoilage. However, it is not wise-and perhaps not even possible - to prevent food from microbial spoilage by production of sterile foods with the exception of heat-treated conserves. Almost all food raw materials contain microbes as do the processing environments.
Microbial food spoilage is a complicated biological phenomenon, a fact that has slowed down development of novel technologies stabilizing food quality during shelf life. The diversity of food spoilage organisms is vast, and on the other hand only a part-referred to as specific spoilage organisms (SSO) or as ephemeral organisms (Gram et al., 2002; Doulgeraki et al., 2012) — of the initial bacterial contaminants causes food spoilage. SSO do not cause human disease, but some psychrotrophic pathogens, such as Listeria monocytogenes and the pathogenic Yersinia species, are able to grow within the cold-tolerant food spoilage communities. Figure 1 shows an example of our studies related to microbial succession in one modified atmosphere packaging (MAP) raw beef product at $6^{\circ} \mathrm{C}$. Packaging gas contained $80 \%$ and $20 \%$ of oxygen and carbon dioxide, respectively. The packages (6 production lots) initially had 850 to 550 operational taxonomic units (OTU) and relatively low bacterial cell levels typical for a fresh raw meat product, i.e., approximately $10^{3}$ colony-forming units $(\mathrm{CFU}) / \mathrm{g}$. The OTU were derived from $16 \mathrm{~S}$ ribosomal ribonucleic acid (rRNA) amplicon sequencing, and they crudely estimate bacterial species diversity in the product. After succession when the product was spoiled, the bacterial communities had reached levels of $10^{8} \mathrm{CFU} / \mathrm{g}$, whereas only one-third of the initial number of OTU were

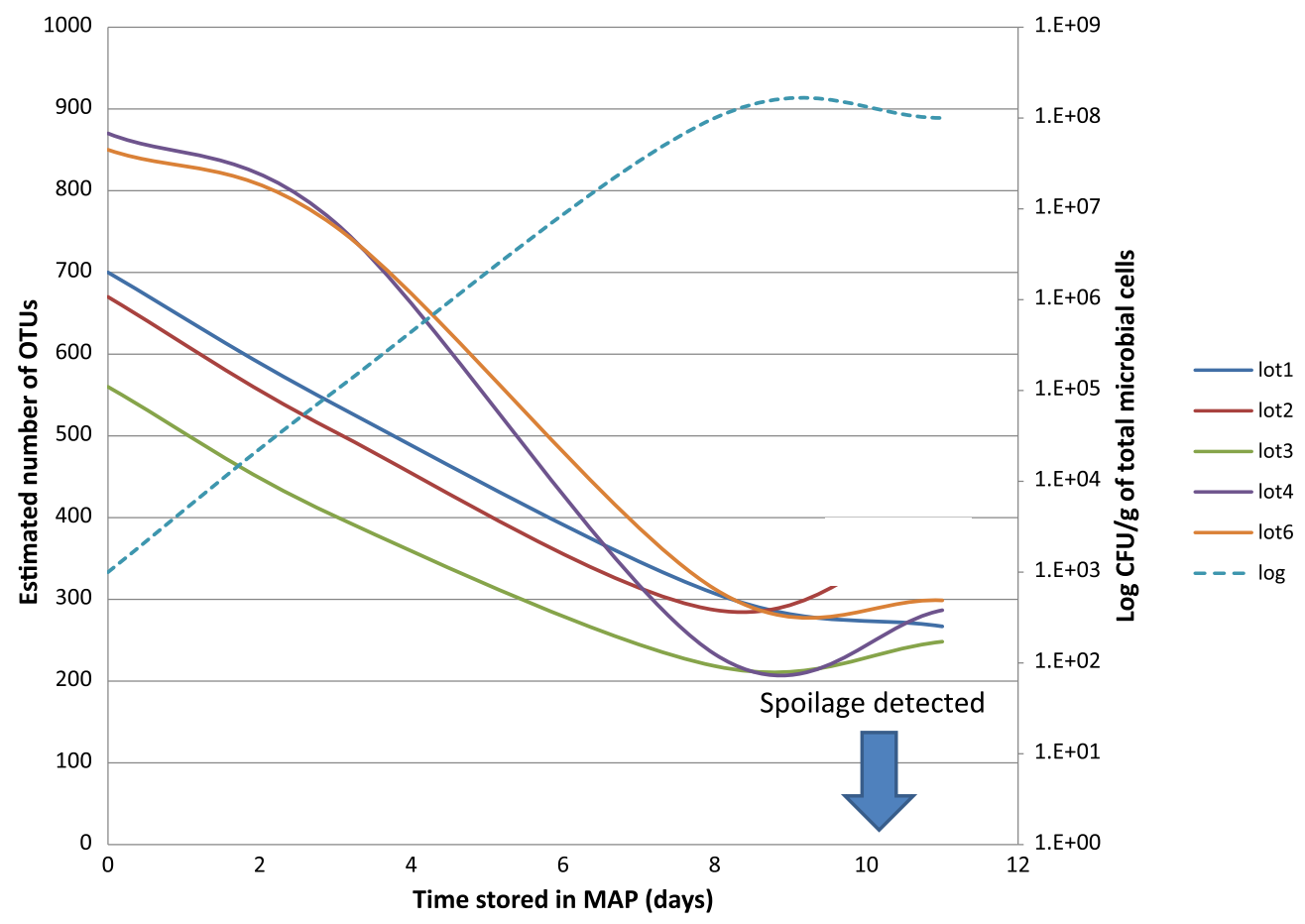

Figure 1. Bacterial succession in a MAP pork product packaged under $30 \%$ and $70 \%$ of carbon dioxide and nitrogen, respectively, and stored at $6{ }^{\circ} \mathrm{C}$. Zerotimeline starts from the time of packaging under modified atmosphere. Sensory panel detected spoilage on day 10 when the bacterial concentration had grown to $10^{8}$ $\mathrm{CFU} / \mathrm{g}$ and OTU number diminished by $60 \%$ to $70 \%$. CFU = colony-forming unit; MAP = modified atmosphere packaging; OTU = operational taxonomic unit. 
detected. These 200 to 300 taxa had been the SSO able to grow and produce spoilage volatiles rendering the product unfit for human consumption in $8 \mathrm{~d}$. But were they the fastest to utilize nutrients, strongest to survive stressors or equipped with capabilities needed in interaction and mutualistic behavior? Nor did we know whether exactly these OTU had contaminated the processing facilities with constant flows or whether they had persisted on certain surfaces or in raw materials. Our current knowledge of cold-tolerant SSO is still quite fragmental, and often it does not allow us to answer the most interesting questions from the food manufacturer's point of view. These questions are mainly related to sources and properties/circumstances allowing SSO to grow in their products.

\section{Genomic Studies With Spoilage- Causing Lactic Acid Bacteria}

We have pioneered studies on cold-tolerant food spoilers. In the 1990s and early 2000s, the team of Professor Björkroth investigated which species and strains were the most important spoilers in perishable foods (Björkroth and Korkeala, 1997a; Björkroth et al., 1998, 2000; Hyytiä-Trees et al., 1999; Lyhs et al., 2001, 2002, 2004; Susiluoto et al., 2003) and how these bacteria contaminated meat products (Björkroth and Korkeala, 1996, 1997b). The team also detected and described several novel food spoilers (Björkroth et al., 2000, 2002; Koort et al., 2004, 2005; Rahkila et al., 2011), of which Leuconostoc gelidum subsp. gasicomitatum has become one of the most studied spoilage lactic acid bacterium (LAB) in Europe in recent years (Pothakos et al., 2014, 2015a, 2015b, 2015c). To adopt genomics and the novel culture-independent approaches for food microbiome studies, the individual teams of Professor Björkroth and Dr. Auvinen established a consortium that has over the years studied questions related to the properties enabling a bacterium to be an SSO and a competitive grower in food microbiomes. We also wanted to better understand the contamination events happening in food processing environments beyond the results that we had obtained using molecular typing techniques.

We started the genomics of SSO LAB by publishing the genome of L. gelidum subsp. gasicomitatum (Johansson et al., 2011) and annotating its spoilageassociated pathways.

It is a fast grower (Andreevskaya et al., 2018) and a versatile spoiler causing the bulging of MAP meat and vegetable packages, green meat discoloration, and buttery off-odors. According to our current knowledge, L. gelidum subsp. gasicomitatum is an environmental LAB not associated with humans or warm-blooded animals. Our studies and others (Pothakos et al., 2014, 2015a, 2015c; Hultman et al., 2015) have shown that it is present in low levels in many types of food manufacturing facilities. It is difficult to produce raw meat or vegetable products without contamination with this bacterium. This is actually typical for many SSO shown by our studies and others. Through genomics, we detected an interesting feature associated with the growth and spoilage potential of $L$. gelidum subsp. gasicomitatum: the strain we sequenced had a functional electron transport chain requiring only externally supplied heme for respiration. We studied this finding further by investigating the respiration effects on growth rate, biomass, gene expression, and volatile organic compound production in laboratory media and pork loin (Jääskeläinen et al., 2013). We observed that functional respiration increased the growth (rate and yield) of L. gelidum subsp. gasicomitatum in laboratory media with added heme and in situ meat with endogenous heme. Respiration increased enormously (up to 2,600-fold) the accumulation of acetoin and diacetyl, which are buttery off-odor compounds in meat. Our transcriptome analyses showed that the gene expression patterns were quite similar, irrespective of whether respiration was turned off by excluding heme from the medium or mutating the $c y d B$ gene, which is essential in the respiratory chain. Respiration is therefore a key factor explaining why L. gelidum subsp. gasicomitatum is so well adapted to grow in highoxygen-packaged meat.

In the first genomic study of L. gelidum subsp. gasicomitatum (Johansson et al., 2011), we noticed that this bacterium had utilization strategies for ribose, external nucleotides, nucleosides, and nucleobases. A whole-genome microarray study, together with gas chromatography-mass spectrometry analyses of the pathway end products, was performed to investigate the transcriptome response of L. gelidum subsp. gasicomitatum LMG18811T growing on semi-defined media containing glucose, ribose, or inosine, which are essential carbon sources in meat (Jääskeläinen et al., 2015). Generally, the gene expression patterns with ribose and inosine were quite similar, indicating that catabolism of ribose and nucleosides is closely linked. Diacetyl/acetoin concentrations as high as 110 or $470 \mu \mathrm{M}$ were measured when growth was based on inosine or ribose, respectively. We did not detect diacetyl production $(<7.5 \mu \mathrm{M})$ with the 
glucose-containing medium, even though the cell counts of LMG18811T were 6 or 10 times higher than those on inosine or ribose, respectively. Although glucose was the most effective carbon source for the growth of L. gelidum subsp. gasicomitatum, utilization of inosine and ribose resulted in the production of the unwanted buttery-odor compounds. These results show that spoilage metabolites may rise from nutrients that are not the most preferred sources for growth.

Along with L. gelidum subsp. gasicomitatum, we modelled other predominant meat spoilage LAB. We had associated Lactococcus piscium with the formation of buttery and sour off-odors (Rahkila et al. 2012) and found that the spoilage potential of L. piscium varies dramatically depending on the strain and growth conditions. Additional knowledge about the genome was required to explain such variation, understand its phylogeny, and study gene functions. Thus, we published the complete and annotated genomic sequence of L. piscium MKFS47, combined with a time course analysis of the glucose catabolismbased transcriptome (Andreevskaya et al., 2015). In addition, we performed a comparative analysis of gene contents for L. piscium MKFS47 and 29 other lactococci, revealing 3 distinct clades within the genus. L. piscium MKFS47 ferments a wide range of carbohydrates and is able to aerobically grow on glycerol. Both carbohydrate and glycerol catabolic pathways were significantly upregulated over the course of time as a result of glucose exhaustion. At the same time, differential expression of the pyruvate utilization pathways, implicated in the formation of spoilage substances, switched the metabolism toward a heterofermentative mode. L. piscium MKFS47 is an efficient producer of buttery-odor compounds under aerobic conditions.

Paucilactobacillus oligofermentans is the third SSO we studied using functional genomics (Andreevskaya et al., 2016). It has been mostly isolated from coldstored packaged meat products in connection with their spoilage, but its precise role in meat spoilage is unknown. The transcriptomic changes detected in $P$. oligofermentans for growth with different carbohydrates differ significantly from those of facultative heterofermentative lactobacilli. The mechanism of Catabolite Control Protein A (CcpA) regulation, putatively contributing to the observed similarities between glucose- and xylose-induced transcriptome responses and the absence of stringent carbon catabolite control, requires further studies. Finally, the cell redox balance maintenance-in terms of the $\mathrm{NAD}(\mathrm{P})+/ \mathrm{NAD}(\mathrm{P}) \mathrm{H}$ ratio-was predicted to be regulated by the Rex transcriptional regulator, supporting the previously made inference of Rex regulons for members of the Lactobacillaceae family.

To increase our knowledge of system-level responses of $\mathrm{LAB}$ during growth, we studied interactions between the 3 previously mentioned SSO, i.e., L. gelidum subsp. gasicomitatum, L. piscium, and $P$. oligofermentans, comparing their time course transcriptome profiles obtained during their growth in individual, pairwise, and triple cultures (Andreevskaya et al., 2018). The study revealed how these LAB employed different strategies to cope with the consequences of interspecies competition. The fastest-growing bacterium, L. gelidum subsp. gasicomitatum, attempted to enhance its nutrientscavenging and growth capabilities in the presence of other LAB through upregulation of carbohydrate catabolic pathways, pyruvate fermentation enzymes, and ribosomal proteins, whereas the slower-growing $L$. piscium and $P$. oligofermentans downregulated these functions. We considered that these findings together with the respiration capability may explain the competitive success and predominance of L. gelidum subsp. gasicomitatum in a variety of spoiled foods. We were also interested in the defense mechanisms interspecies interactions might induce during cocultivation. $L$. piscium and $P$. oligofermentans induced overexpression of prophage genes and restriction modification systems (mechanisms of DNA exchange and protection against it), but L. gelidum did not show any known defense response.

\section{Microbiomes Associated With Food Spoilage}

To increase our understanding of food spoilage, we need more information about microbiomes associated with food spoilage. These microbiomes can be scrutinized at different levels, i.e., in relation to the primary production environment, raw materials, and processing facilities together with operational personnel and other sources of microbial contamination. Figure 2 shows connections between the different microbiota associated with a product and its manufacturing environment. It also shows how the microbiomes of a packaged food product are developing under the selective pressures related to refrigeration and packaging atmosphere over the course of time. This longitudinal development of spoilage 
Microbial food spoilage

Metabolic activities of spoilage microbes resulting in

unpleasant odors, tastes, and textures.

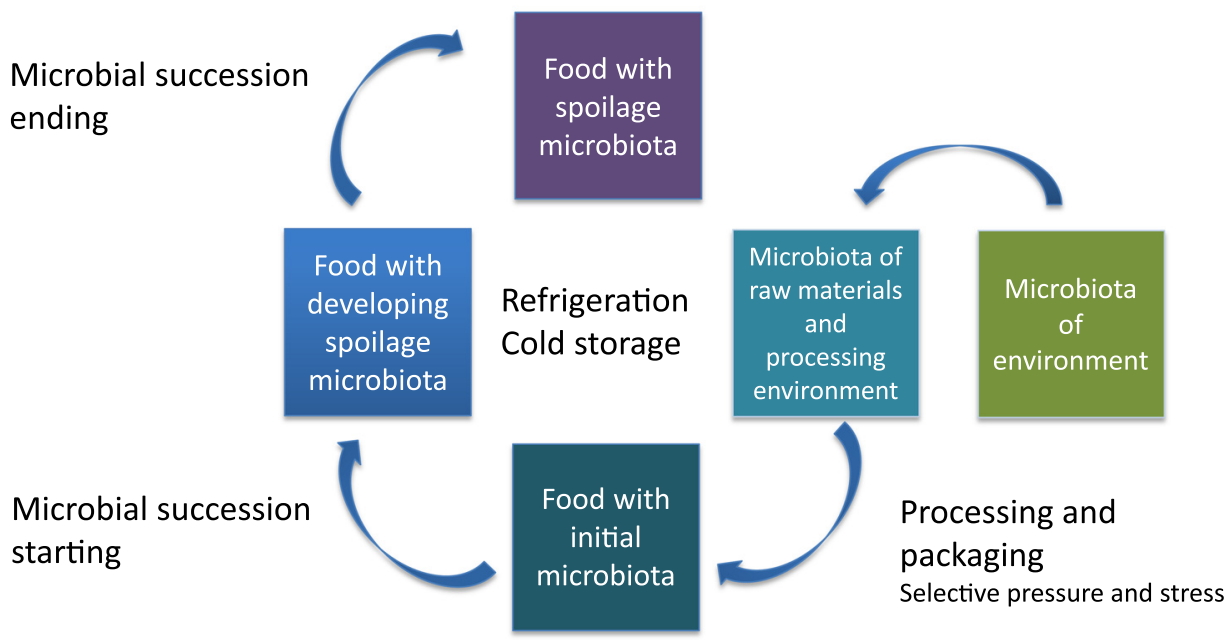

Figure 2. Microbiomes associated with manufacture of MAP meat products. MAP = modified atmosphere packaging.

microbiomes explains why it is often difficult to answer questions related to product contamination and subsequent spoilage events. All microbiomes associated with food spoilage are changing constantly, making understanding of the causal relationships between a contamination cascade/event and the developing spoilage microbiome difficult.

\section{Terminal Restriction Fragment Length Polymorphism Analysis Applied in Meat Microbiome Studies}

Before we established the methods based on amplicon or other sequencing technologies, we used cultureindependent characterization of LAB communities by terminal restriction fragment length polymorphism (T-RFLP) to study how packaging atmosphere affects SSO communities (Nieminen et al., 2015). We inoculated raw pork loin with a mixture of 14 LAB strains commonly associated with meat and used 4 different gas atmospheres for packaging: (i) $100 \% \mathrm{CO}_{2}$; (ii) $80 \% \mathrm{~N}_{2}, 20 \% \mathrm{CO}_{2}$; (iii) $80 \% \mathrm{~N}_{2}, 20 \% \mathrm{CO}_{2}, 0.4 \%$ $\mathrm{CO}$; and (iv) $80 \% \mathrm{O}_{2}, 20 \% \mathrm{CO}_{2}$. We monitored the packages every other day during the storage of $14 \mathrm{~d}$ at $+6^{\circ} \mathrm{C}$. The compositions of LAB communities on pork were evaluated after $7 \mathrm{~d}$ of storage with cultureindependent T-RFLP of 16S rRNA gene fragments. The results showed that (i) high concentration of $\mathrm{CO}_{2}$ in packaging atmosphere favored Lactobacillus spp., (ii) high concentration of $\mathrm{O}_{2}$ favored Leuconostoc spp., and (iii) atmosphere with $80 \% \mathrm{~N}_{2}, 20 \% \mathrm{CO}_{2}$ favored Lactococcus spp. Thus, this microbiome study also showed the association of Leuconostoc with oxygen-containing modified atmosphere.

We investigated the effect of marination, marinade components, and storage time on composition of bacterial communities in MAP broiler fillet strips (Nieminen et al., 2012a, 2012b). In this study, we characterized the microbiomes using 2 culture-independent methods: 16S rRNA gene amplicon sequencing and TRFLP. In unmarinated broiler fillet strips, Lactococcus spp. and Carnobacterium spp. predominated at the early storage phase but were partially replaced by Lactobacillus spp. and Leuconostoc spp. when the chilled storage time was extended. In the marinated fillet strips, Lactobacillus spp. and Leuconostoc spp. predominated independent from the storage time. By mixing the different marinade components with broiler meat, we showed that marination changed the community composition and favored Leuconostoc spp. and Lactobacillus spp. by the combined effect of carbohydrates and acetic acid in marinade. Marination increased the maximum level of $\mathrm{LAB}$ in broiler meat and enhanced $\mathrm{CO}_{2}$ production and acidification of meat during the chilled storage. Accumulation of $\mathrm{CO}_{2}$ in package head-space due to the enhanced growth of Leuconostoc spp. in marinated meat may lead to bulging of packages, which is a spoilage defect frequently associated with marinated and MAP raw broiler preparations. 


\section{$16 S$ rRNA Gene Amplicon Sequencing for Quantification of Taxa Associated With Meat Spoilage}

Polymerase chain reaction-based quantification of taxa, especially by $16 \mathrm{~S}$ rRNA gene amplicon sequencing, is nowadays a popular method to study microbial communities despite the limitations and possible methodological pitfalls (Bonk et al., 2018). We used this approach in the studies related to the development of spoilage microbiomes in marinated products (Nieminen et al., 2012b) and under different packaging atmospheres (Jääskeläinen, et al. 2016) over the course of time. We also applied a 16S rRNA gene amplicon sequencing approach for studying the contamination of processing environment (Hultman et al., 2015).

Prompted by a study related to the effect of gas atmosphere on inoculated meat (Nieminen et al., 2012a), we wanted to investigate the influence of packaging (under vacuum and in high-oxygen atmosphere) on the development of microbiomes and metabolic activities at $6^{\circ} \mathrm{C}$ in commercial beef. In this study, we used culture-dependent (cultivation, ribotyping database for identification of the isolates) and culture-independent (16S rRNA gene amplicon sequencing) methods. At the beginning of shelf life, the microbial community mostly consisted of Carnobacterium and Lactobacillus. After 2 wk of storage, Lactococcus and Lactobacillus were the dominant genera under vacuum, and Leuconostoc was dominant in high-oxygen meat packages. Also, this study indicated that oxygen favors the growth of the genus Leuconostoc. The number of volatile compounds - such as diacetyl, 1-octen-3-ol and hexanoic acids-was higher in high-oxygen packages than under vacuum. The beef under high-oxygen atmosphere was detected as spoiled in sensory evaluation over $10 \mathrm{~d}$ earlier than beef under vacuum. L. gelidum, L. piscium, Lactobacillus sakei, and Lactobacillus algidus were the most common species based on the culturing and ribotyping approaches. The results obtained from identification of the isolates using ribotyping and amplicon sequencing correlated, except for L. algidus, which was detected in both types of packaging by amplicon sequencing, but only in vacuum-packaged samples using the culture-based technique. This indicates that L. algidus grew but was not cultivable in high-oxygen beef using the Nordic Committee on Food Analysis standard method. Säde et al. (2019) recently published an improved method for culturing of this species.
It is good to understand that culturing and cultureindependent approaches may lead to different outcomes.

\section{Processing Facilities Related to Sausage Manufacture}

We also applied 16S rRNA gene amplicon sequencing in a study of a sausage processing facility to investigate the link between processing plant and product microbiomes (Hultman et al, 2015). We followed and compared microbiota associated with the raw materials and processing stages of a vacuumpackaged, cooked sausage product affected by a prolonged quality fluctuation with occasional spoilage manifestations during shelf life. A total of 195 samples were subjected to culturing and amplicon sequence analyses. Abundant mesophilic psychrotrophs were detected within the microbiomes throughout the different compartments of the production plant environment. However, each of the main genera of food safety and quality interest, such as Leuconostoc and Yersinia, had their own characteristic patterns of contamination. Sausages were spoiled mainly by leuconostocs. The same OTU were detected in lower abundances in raw meat and emulsion, as well as on the processing plant surfaces. Leuconostocs were able to grow well in the product, and we suspected that certain surfaces had contaminated the sausages after cooking. We found a completely different abundance profile for OTU phylogenetically close to the pathogenic species $Y$. pseudotuberculosis. These OTU were detected in high abundance on the processing plant surfaces but to a lesser extent in raw meat, sausage emulsion, and cooked sausages. The fact that we found Yersinia-like OTU on the surfaces of a high-hygiene packaging compartment raised food safety concerns related to their resilient existence on surfaces.

\section{Metagenome and Metatranscriptome Studies of Meat Spoilage Microbiota}

Since we detected premature spoilage of marinated poultry preparations and associated it with high levels of Leuconostoc spp. in meat (Björkroth et al., 2000), we wanted to investigate further whether marination of broiler fillet strips increased the proportion of Leuconostoc spp. in the spoilage microbiomes (Nieminen et al., 2012a). The marinade consisted of 
glucose, maltodextrin, honey, vinegar, rapeseed oil, $\mathrm{NaCl}$, spices (sweet pepper, curry, black pepper, garlic, turmeric), and yeast extract. The acetic acid concentration in the marinade was $0.45 \%(w t / w t)$. Marinated preparation contained $15 \%(\mathrm{wt} / \mathrm{wt})$ of marinade and $85 \%$ of brined strips. The product was packaged under $65 \%$ and $35 \%$ nitrogen and carbon dioxide, respectively, and was kept at $6^{\circ} \mathrm{C}$. To obtain a comprehensive view of the microbiota, we sequenced total DNA and 16S rRNA gene amplicons from the microbial communities. For detailed colony counts and $\mathrm{pH}$ levels, please see table 1 by Nieminen et al. (2012a). The LAB communities were characterized also by identification of colonies using culturing and our ribotyping database. The results showed that marinade increased the proportions of spoilage-associated L. gelidum subsp. gasicomitatum in the microbiomes as well as the proportions of the other L. gelidum subspecies and Lactobacillus spp. The proportions of Carnobacterium, Vagococcus, Brochothrix thrermosphacta, Clostridium, Enterobacteriaceae, and Vibrio were diminished in marinated meat. Analysis of $16 \mathrm{~S}$ rRNA gene amplicons resulted in 312 and 284 OTU (dissimilarity 0.03) in unmarinated and marinated meat, respectively, indicating that the meat communities were more diverse than we thought before. Metagenomic analysis revealed a number of bacterial taxa that have not commonly been associated with spoiled meat before, including Vagococcus and Vibrio that belonged to the predominating part of the microbial community in unmarinated meat. According to the functional analysis of the metagenomes, the communities in both marinated and unmarinated poultry were characterized by high proportions $(15.6 \%$ or $17.9 \%)$ of genes involved in carbohydrate metabolism.

Currently, we have been investigating longitudinal metatranscriptomes associated with spoilage of highoxygen-packaged beef. We learned from the metagenome study that it would be necessary to know which species and pathways are the most active during spoilage over the course of time. In our latest study, we studied whether we can distinguish which stage the active microbiome has based on species composition and gene transcription. The active microbiome and genes had 3 stages that were descriptive for the quality of the beef. All 3 stages shared species and functions, but there were several distinct metabolic features in each stage. Psychrotrophic LAB formed the core of the SSO as usual. Leuconostoc species were the most abundant of the active microbes throughout the study period, whereas Lactococcus activity increased after the product was spoiled. The community managed environmental stress, first by active cold-shock responses and then by expression of genes involved in managing oxidative stress from day 6 onward. Contrary to our hypothesis, carbohydrate fermentation did not cease in late spoilage. This study provides additional evidence of the fast onset of leuconostoc growth that is later followed by other species in the microbiome, as in this case psychrotrophic lactococci. Results from our experiment show that, instead of measuring bacterial cell numbers for product quality evaluation, the focus should be on more detailed activity markers related to food spoilage.

\section{Literature Cited}

Andreevskaya, M., P. Johansson, P. Laine, O.-P. Smolander, M. Sonck, Rahkila, R., Jääskeläinen, E., Paulin, L., Auvinen, P., and Björkroth, J. 2015. Genome sequence and transcriptome analysis of meat spoilage lactic acid bacterium Lactococcus piscium MKFS47. Appl. Environ. Microb. 81:3800-3811. https://doi.org/10.1128/AEM.00320-15.

Andreevskaya, M., P. Johansson, E. Jääskeläinen, T. Rämö, J. Ritari, L. Paulin, J. Björkroth, and P. Auvinen. 2016. Lactobacillus oligofermentans glucose, ribose and xylose transcriptomes show higher similarity between glucose and xylose catabolism-induced responses in the early exponential growth phase. BMC Genomics. 17:539. https://doi.org/10. 1186/s12864-016-2840-x.

Andreevskaya, M., E. Jääskeläinen, P. Johansson, R. Rahkila, T. Nieminen, L. Paulin, J. Björkroth, and P. Auvinen. 2018. Food-spoilage-associated Leuconostoc, Lactococcus, and Lactobacillus species display different survival strategies in response to competition. Appl. Environ. Microb. 84: e00554-18. https://doi.org/10.1128/AEM.00554-18.

Björkroth, K. J., and H. J. Korkeala. 1996. Evaluation of Lactobacillus sake contamination in vacuum packaged sliced cooked meat products by ribotyping. J. Food Protect. 59:398401. https://doi.org/10.4315/0362-028X-59.4.398.

Björkroth, K. J., and H. J. Korkeala. 1997a. Lactobacillus fructivorans spoilage of tomato ketchup. J. Food Protect. 60:505-509. https://doi.org/10.4315/0362-028X-60.5.505.

Björkroth, K. J., and H. J. Korkeala. 1997b. Use of rRNA gene restriction patterns to evaluate lactic acid bacterium contamination of vacuum-packaged sliced cooked whole-meat product in a meat processing plant. Appl. Environ. Microb. 63:448-453.

Björkroth, K. J., P. Vandamme, and H. J. Korkeala. 1998. Identification and characterization of Leuconostoc carnosum associated with production and spoilage of vacuum-packaged sliced cooked ham. Appl. Environ. Microb. 64:3313-3319.

Björkroth, K. J., R. Geisen, U. Schillinger, N. Weiss, P. De Vos, W. H. Holzapfel, H. J. Korkeala, and P. Vandamme. 2000. Characterization of Leuconostoc gasicomitatum sp. nov. associated with spoiled raw tomato-marinated broiler meat strips packaged under modified atmosphere conditions. Appl. 
Environ. Microb. 66:3764-3772. https://doi.org/10.1128/ aem.66.9.3764-3772.2000.

Björkroth, K. J., U. Schillinger, R. Geisen, N. Weiss, W. H. Holzapfel, H. J. Korkeala, B. Hoste, and P. Vandamme. 2002. Taxonomic study of Weissella confusa and description of Weissella cibaria sp. nov., a novel species detected in food and clinical samples. Int. J. Syst. Evol. Micr. 52:141-148. https://doi.org/10.1099/00207713-52-1-141.

Bonk, F., D. Popp, H. Harms, and F. Centler. 2018. PCR-based quantification of taxa-specific abundances in microbial communities: Quantifying and avoiding common pitfalls. J. Microbiol. Meth. 153:139-147. https://doi.org/10.1016/j. mimet.2018.09.015.

Bourdichon, F., and K. Rouzeau. 2012. Microbial food spoilage: A major concern for food business operators. New Food. Issue 3. https://www.newfoodmagazine.com/article/8180/microbialfood-spoilage-a-major-concern-for-food-business-operators/ . (Accessed 24 June 2020).

Doulgeraki, A. L., D. Ercolini, F. Villani, and G.-E. J. Nychas. 2012. Spoilage microbiota associated to the storage of raw meat in different conditions. Int. J. Food Microbiol. 157:130-141. https://doi.org/10.1016/j.ijfoodmicro.2012.05. 020 .

Gram, L., L. Ravn, M. Rasch, J. B. Bruhn, A. B. Christensen, and M. Givskov. 2002. Food spoilage_-interactions between food spoilage bacteria. Int. J. Food Microbiol. 15:79-97. https:// doi.org/10.1016/S0168-1605(02)00233-7.

Hultman, J., R. Rahkila, J. Ali, J. Rousu, and K. J. Björkroth. 2015. Meat processing plant microbiome and contamination patterns of cold-tolerant bacteria causing food safety and spoilage risks in manufacture of vacuum-packaged cooked sausages. Appl. Environ. Microb. 81:7088-7097. https://doi.org/10. 1128/AEM.02228-15.

Hyytiä-Trees, E., U. Lyhs, H. Korkeala, and J. Björkroth. 1999. Characterisation of ropy slime-producing Lactobacillus sakei using repetitive element sequence-based PCR. Int. J. Food Microbiol. 50:215-219. https://doi.org/10.1016/S0168-1605 (99)00104-X.

Jääskeläinen, E., P. Johansson, O. Kostiainen, T. Nieminen, G. Schmidt, P. Somervuo, M. Mohsina, P. Vanninen, P. Auvinen, and J. Björkroth. 2013. Significance of heme-based respiration in meat spoilage caused by Leuconostoc gasicomitatum. Appl. Environ. Microb. 79:1078-1085. https://doi.org/ 10.1128/AEM.02943-12.

Jääskeläinen, E. L., S. Vesterinen, J. Parshintsev, P. Johansson, M.-L. Riekkola, and J. Björkroth. 2015. Production of buttery-odor compounds and transcriptome response in Leuconostoc gelidum subsp. gasicomitatum LMG18811(T) during growth on various carbon sources. Appl. Environ. Microb. 81:1902-1908. https://doi.org/10.1128/AEM. 03705-14.

Jääskeläinen, E., J. Hultman, J. Parshintsev, M.-L. Riekkola, and J. Björkroth. 2016. Development of spoilage bacterial community and volatile compounds in chilled beef under vacuum or high oxygen atmospheres. Int. J. Food Microbiol. 223:25-32. https://doi.org/10.1016/j.ijfoodmicro.2016.01.022.

Johansson, P., L. Paulin., E. Säde, N. Salovuori, E. R. Alatalo, K. J. Björkroth, and P. Auvinen. 2011. Genome sequence of a food spoilage lactic acid bacterium Leuconostoc gasicomitatum
LMG $18811^{\mathrm{T}}$, in association with specific spoilage reactions. Appl. Environ. Microb. 77:4344-4351. https://doi.org/10. 1128/AEM.00102-11.

Koort, J.M.K., T. Coneye, P. Vandamme, A. Sukura, and J. Björkroth. 2004. Enterococcus hermanniensis sp. nov., from modified-atmosphere-packaged broiler meat and canine tonsils. Int. J. Syst. Evol. Micr. 54:1823-1827. https://doi.org/ 10.1099/ijs.0.63112-0.

Koort, J. M. K., A. Murros, T. Coneye, S. Eerola, P. Vandamme, A. Sukura, and K. J. Björkroth. 2005. Lactobacillus oligofermentans sp. nov., associated with spoilage of modified-atmosphere-packaged poultry products. Appl. Environ. Microb. 71:4400-4406. https://doi.org/10.1128/AEM.71.8.44004406.2005 .

Lyhs, U., H. Korkeala, P. Vandamme, and J. Björkroth. 2001. Lactobacillus alimentarius: A specific spoilage organism in marinated herring. Int J. Food Microbiol. 64:355-360. https://doi.org/10.1016/S0168-1605(00)00486-4.

Lyhs, U., H. Korkeala, P. Vandamme, and J. Björkroth. 2002. Identification of lactic acid bacteria from spoiled, vacuumpackaged, gravad rainbow trout using ribotyping. Int. J. Food. Microbiol. 72:147-153. https://doi.org/10.1016/ s0168-1605(01)00634-1.

Lyhs, U., J. M. K. Koort, H.-S. Lundström, and J. Björkroth. 2004. Leuconostoc gelidum and Leuconostoc gasicomitatum strains dominated the lactic acid bacterium population associated with strong slime formation in an acetic-acid herring preserve. Int. J. Food Microbiol. 90:207-248. https://doi.org/10.1016/ s0168-1605(03)00303-9.

Nieminen, T., K. Koskinen, P. Laine, J. Hultman, L. Paulin, S. Säde, A. Paloranta, P. Johansson, J. Björkroth, and P. Auvinen. 2012a. Comparison of microbial communities in marinated and unmarinated broiler meat by metagenomics. Int. J. Food Microbiol. 157:142-149. doi:10.1016/j. ijfoodmicro.2012.04.016.

Nieminen, T. T., H. Välitalo, E. Säde, A. Paloranta, K. Koskinen, and J. Björkroth. 2012b. The effect of marination on lactic acid bacteria communities in raw broiler fillet strips. Front. Microbiol. 3:376. https://doi.org/10.3389/fmicb.2012. 00376.

Nieminen, T. T., M. Nummela, and J. Björkroth. 2015. Packaging gas selects lactic acid bacterial communities on raw pork. J. Appl. Microbiol. 119:1364-5072. https://doi.org/10.1111/ jam. 12890.

Pothakos, V., C. Snauwaert, P. De Vos, G. Huys, and F. Devlieghere. 2014. Psychrotrophic members of Leuconostoc gasicomitatum, Leuconostoc gelidum and Lactococcus piscium dominate at the end of shelf-life in packaged and chilled-stored food products in Belgium. Food Microbiol. 39:61-67. https://doi.org/10.1016/j.fm.2013.11.005.

Pothakos, V., Y. A. Aulia, I. Van Der Linden, M. Uyttendaele, and F. Devlieghere. 2015a. Exploring the strain-specific attachment of Leuconostoc gelidum subsp. gasicomitatum on food contact surfaces. Int. J. Food Microbiol. 199;41-46. https:// doi.org/10.1016/j.ijfoodmicro.2015.01.008.

Pothakos, V., F. Devlieghere, F. Villani, J. Björkroth, and D. Ercolini. 2015b. Lactic acid bacteria and their controversial role in fresh meat spoilage. Meat Sci. 109:66-74. https:// doi.org/10.1016/j.meatsci.2015.04.014. 
Pothakos, V., G. Stellato, D. Ercolini, and F. Devlieghere. 2015c. Processing environment and ingredients are both sources of Leuconostoc gelidum, which emerges as a major spoiler in ready-to-eat meals. Appl. Environ. Microb. 81:3529-3541. https://doi.org/10.1128/AEM.03941-14.

Rahkila, R., P. Johansson, E. Säde, and J. Björkroth. 2011. Identification of enterococci from broiler products and broiler processing plant and description of Enterococcus viikkiensis sp. nov. Appl. Environ. Microb. 77:1196-1203. https://doi. org/10.1128/AEM.02412-10.

Rahkila, R., T. Nieminen, P. Johansson, E. Säde, and J. Björkroth. 2012. Characterization and evaluation of the spoilage potential of Lactococcus piscium isolates from modified atmosphere packaged meat. Int. J. Food Microbiol. 156:50 59. https://doi.org/10.1016/j.ijfoodmicro.2012.02.022.

Säde, E., P. Johansson, T. Heinonen, J. Hultman, and J. Björkroth. 2019. Growth and metabolic characteristics of fastidious meat-derived Lactobacillus algidus strains. Int. J. Food Microbiol. 313:108379. https://doi.org/10.1016/ j.ijfoodmicro.2019.108379.

Susiluoto, T., H. Korkeala, and J. Björkroth. 2003. Leuconostoc gasicomitatum is the dominating lactic acid bacterium in retail modified-atmosphere-packaged marinated broiler meat strip products on sell by day. Int. J. Food Microbiol. 80:89-97. https://doi.org/10.1016/s0168-1605(02)00123-x. 